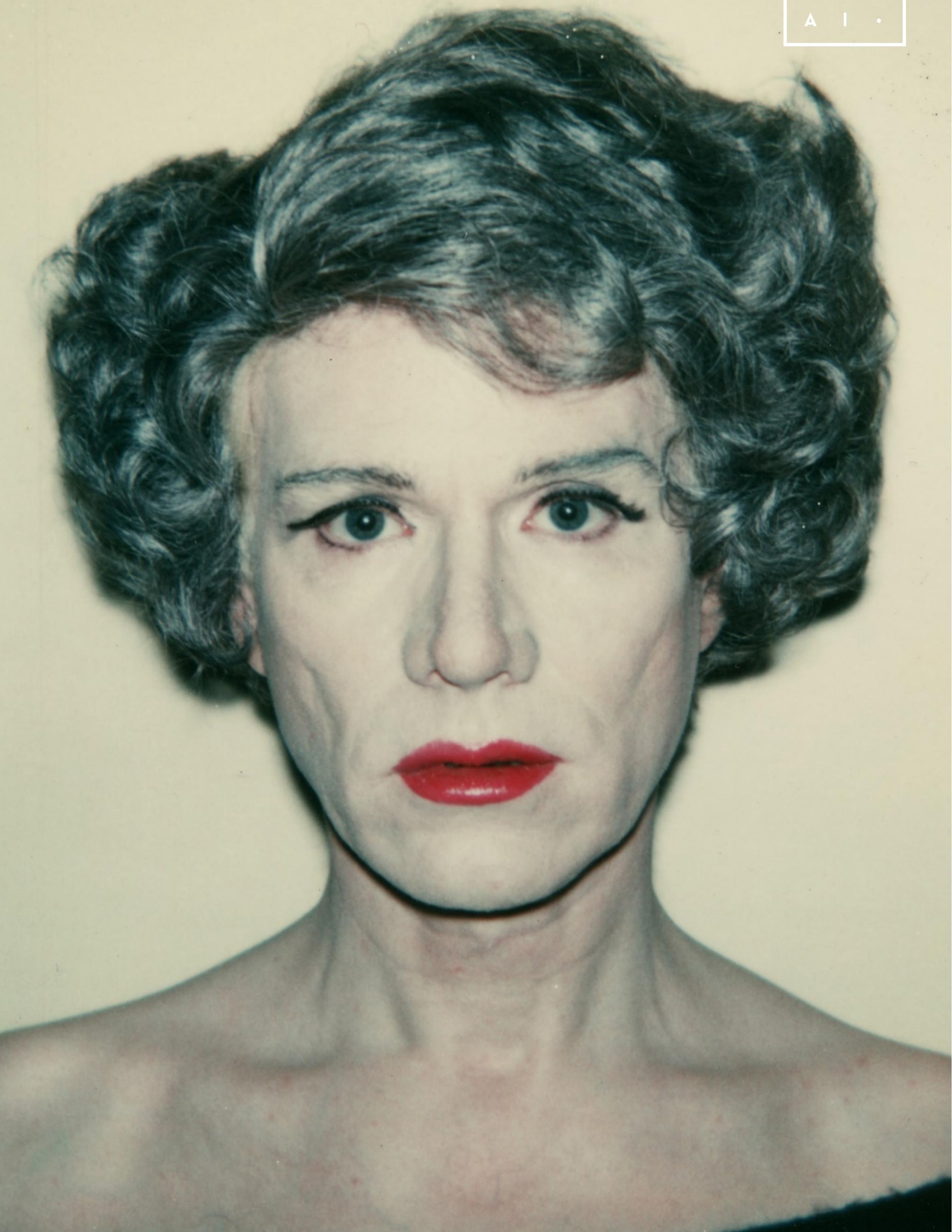




\section{OS “ARQUIVOS DA REPRESS ÃO” \\ DAS DITADURAS DE SEGURANÇA NACIONAL DO CONE SUL}

LOS “ARCHIVOS DE LA REPRESIÓN” DE LAS DICTADURAS DE SEGURIDAD NACIONAL DEL CONO SUR

THE “ARCHIVES OF THE REPRESSION” OF THE NATIONAL SECURITY DICTATORSHIPS OF THE SOUTH CONE 
RESUMO / RESUMEN / ABSTRACT

Resumo: O artigo tece considerações acerca dos "arquivos da repressão", suas características, alcances e particularidades, fatores que impulsionam tanto as práticas arquivísticas como o conhecimento histórico acerca das Ditaduras de Segurança Nacional implantadas no Cone Sul a partir da década de 1960. Verifica-se que a imprecisão e uso indiscriminado desse termo por vezes pretere a importância de outros tipos de acervos documentais vinculados às instituições repressivas, também importantes para os esclarecimentos colocados às questões de Memória, Verdade e Justiça. Entende-se que os arquivos de organismos de Estado, conectados com os acervos privados, os das Comissões para a Verdade, assim como os das organizações de Direitos Humanos e de Organismos Internacionais, aliam-se à proteção do exercício de direitos cidadãos, tanto coletivos quanto individuais.

Palavras-chave: Cone Sul. Ditadura. Arquivos da repressão.

Resumen: El artículo presenta consideraciones acerca de los "archivos de la represión”, sus características, los alcances y las especificidades, factores que impulsan tanto las prácticas archivísticas como el conocimiento histórico acerca de las dictaduras de Seguridad Nacional en el Cono Sur desplegadas desde la década de 1960. Se verifica que la vaguedad y el uso indiscriminado del término a veces desestiman la importancia de otros tipos de fondos documentales relacionados con instituciones represivas también importantes para comprender las cuestiones colocadas a la Memoria, Verdad y Justicia. Se entiende que los archivos de organismos estatales, enlazados con las colecciones privadas, las de las Comisiones de la Verdad, así como las de las organizaciones de Derechos Humanos y Organizaciones Internacionales, se alían para resguardar el ejercicio de los derechos ciudadanos, tanto colectivos como individuales.

Palabras Clave: Cono Sur. Dictadura. Archivos de la represión.

Abstract: The article presents considerations about the "archives of repression", their characteristics, reach and peculiarities, as well as the factors driving both archival practices and as historical knowledge about the National Security dictatorships in the South Cone deployed from the 1960s. It appears that the haziness and indiscriminate use of the term sometimes hinders proper consideration of the importance of other types of documentary collections linked to the repressive institutions, also important for clarification posed to issues about Memory, Truth and Justice. It is understood that the files of State agencies connected with private collections, those of Commissions for Truth, as well as those of Human Rights and International Organizations, are allied to the protection of the exercise of citizenship rights, both collective and individual.

Keywords: South Cone. Dictatorship. Archives of Repression. 


\section{INTRODUÇÃO}

"Un bombazo sobre la culpabilidad de Pinochet, recibido muy tarde", é o título da matéria publicada por John Dinges, em outubro de 2015, acerca dos informes desclassificados da CIA que "poderiam ter modificado a história”, ao comprovarem o envolvimento direto do ditador Augusto Pinochet no atentado à bomba que vitimou Orlando Letelier, ex-embaixador do governo de Salvador Allende, em setembro do ano de 1976, em Washington. Para o atual embaixador do Chile nesta cidade - entrevistado pelo autor da matéria - essa documentação, se tivesse sido conhecida quando de sua produção, teria feito com que a posição de Pinochet como Chefe das Forças Armadas se tornasse insustentável. O embaixador acrescenta que, pelo fato de essa documentação remontar pelo menos ao ano de 1978, o retorno à democracia teria acontecido muito antes de quando se deu - somente no ano de 1990 -, destacando como ponto principal o de que o ditador certamente não participaria no processo eleitoral que levou à redemocratização chilena. Dinges salienta que as marcas de classificação dos documentos ainda podem ser vistas - SECRETO y NEGAR -, mas que foram tachadas e substituídas pelo selo PUBLICAR EN TODO, há mais de três décadas da constatação, por parte da CIA, das evidências da culpabilidade do ditador no atentado terrorista (DINGES, 2015).

A centralidade dos debates acerca da desclassificação dos arquivos das ditaduras de Segurança Nacional do Cone Sul impulsiona cada vez mais as sociedades na promoção do debate público sobre a importância do acesso irrestrito às informações contidas nos chamados "arquivos da repressão", fato este que pode ser evidenciado no slogan da atual campanha promovida pelo coletivo chileno Londres 38 Espacio de Memorias -! No más archivos secretos! ¡A romper los pactos de silencio!

A perspectiva de que a documentação dos arquivos relativos ao Terror de Estado ${ }^{2}$ perpetrado pelas ditaduras latino-americanas possibilite conhecer "toda a verdade" desse período faz com que eles sejam não somente resguardados, mas buscados intensamente, ainda hoje. Fator preponderante para tal, por certo, é a impunidade e ocultação da verdade, criando sérios entraves para o resgate das memórias e a formação de uma consciência histórica, obtenção da Justiça, o trabalho de pesquisadores, e, em uma visão ampla da questão, a verificação de que os arquivos da repressão têm por mote primordial a questão dos Direitos Humanos.

Nesse sentido, neste artigo realizamos algumas considerações acerca dos "arquivos da repressão", suas características, alcances e aspectos metodológicos particulares, fatores que repercutem quer no trabalho arquivístico como no historiográfico, que se encontram

${ }^{2}$ Conforme Enrique Serra Padrós o Terror de Estado (TDE) “é uma modalidade essencialmente distinta do terrorismo individual ou de grupos extremados não estatais. Enquanto este é responsabilidade de indivíduos que utilizam a violência de forma indiscriminada para atingir e desestabilizar o Estado e a sociedade, o TDE se fundamenta na lógica de governar mediante a intimidação. É um sistema de governo que emprega o terror para enquadrar a sociedade e que conta com o respaldo dos profundamente imbricados no processo de identificação, tratamento e análise desses arquivos.

\section{OS “ARQUIVOS DA REPRESSÃO”}

Partindo pela definição conceitual de o que sejam considerados "arquivos da repressão", Ludmila da Silva Catela os define, relacionando-os às ditaduras do Cone Sul, como o "conjunto de objetos secuestrados a las víctimas o producidos por las fuerzas de seguridad (policías, servicios de inteligencia, fuerzas armadas) en acciones repressivas (allanamientos, persecución, secuestros, torturas, desaparición, asesinatos, etc)" (DA SILVA CATELA, 2002, p. 209-210), estando incluídos nesta categoria, muitas vezes, os acervos produzidos por instituições de Direitos Humanos com base em suas ações de denúncia e busca de informações relativas aos fatos da repressão.

Ressaltando que ao momento das transições democráticas a documentação tinha como objetivo principal seu uso imediato como prova de verdade e justiça, paulatinamente derivando para o uso do arquivo para a memória e à história, Elizabeth Jelin situa três tipos de acervos arquivístico: o primeiro deles são os acervos das instituições repressivas, citando como exemplos os arquivos do Departamento de Ordem política e Social (DOPS), do Brasil; o Arquivo do Terror, no Paraguai; e o Arquivo da Direção de Inteligência da Polícia da Província de Buenos Aires (DIPPBA); os outros dois tipos seriam os acervos acumulados com base em listas e denúncias de casos, sustentados no trabalho realizado anteriormente pelas organizações de Direitos Humanos, como é o caso dos arquivos das Comissões da Verdade; e acervos dispersos e diversos, com base em resistências pessoais e coletivas, e que se estendem no tempo ao período pós-ditadura, principalmente quando vinculam a memória aos seus objetivos (JELIN, 2002, p.7). Então, os arquivos da repressão tomados são aqueles produzidos pelos órgãos das forças de segurança; os acervos de instituiçães repressivas relacionados com os arquivos policiais e de inteligência. Reforçando esta perspectiva, Marcia Miranda, tendo como referencial o trabalho de Catela sobre os arquivos da repressão no Brasil, nos remete à importância da preservação dos arquivos das instituições de repressão - identificados aos arquivos da repressão e aqueles sobre a atividade repressiva do Estado - que se equivaleriam aos arquivos sobre a repressão - (MIRANDA, 2011, p. 12), sendo os últimos constituídos, dentre outros, pela documentação produzida e acumulada pelas organizações de Direitos Humanos na denúncia do atuar repressivo do Estado. Pese

setores dominantes, mostrando a vinculação intrínseca entre Estado, governo e aparelho repressivo". Ver: Padrós $(2005$, p. 22; 65). A concepção de guerra "total" implica em uma violação permanente dos Direitos Humanos, pois na lógica do TDE todos os meios para vencer o "marxismo internacional" se justificam, dentre eles a delação, tortura, extorsão e desaparecimentos forçados. 
a confusão terminológica, verifica-se a profunda ambiguidade desta distinção, pois essa atividade repressiva do Estado pode ser encontrada nos arquivos de seus órgãos para tal fim criados, propriamente ditos; nos acervos das instituições de Estado; e nos arquivos "alternativos", como bem os denomina Jelin para aqueles voltados fundamentalmente às denúncias de pessoas afetadas, testemunhos pessoais e registros de imprensa (JELIN, 2002, p. 5-6).

Ponto importante a reter é que as Ditaduras de Segurança Nacional ${ }^{3}$ têm como característica intrínseca à sua existência a clandestinidade das operações executadas por seus diferentes órgãos de repressão. No entanto, cabe destacar que, paralelo a essa ação clandestina do Estado, as ditaduras civil-militares, contando com estritas cadeias de comando, contavam com uma organização burocrático-militar que perpassava toda a organização estatal, determinando a hierarquia da instituição e a distribuição de deveres, responsabilidades e "tarefas" correspondentes aos seus diferenciados e múltiplos órgãos e entidades. Jelin destaca essa hierarquização nas diversas instituições - que ela identifica como sendo as polícias e forças armadas, e dentro delas entre as diferentes armas -, uma cadeia burocrática de ordens cumpridas que "implica registros e archivos, organizados, típicos de la actuación policial 'normal"' (JELIN, 2002, p. 4). Porém, onde situar, nessa "hierarquia dos arquivos da repressão", os demais órgãos que compõem a estrutura governamental, como, por exemplo, o Ministério de Relações Exteriores do Chile (MINREL), um dos pilares fundamentais, ao lado dos Ministérios do Interior e da Defesa, para a legitimação da ditadura perante o mundo, responsável pela negação sistemática, diante dos organismos internacionais e, por extensão, dos nacionais, dos desaparecimentos, torturas, prisões e toda a sorte de violações massivas dos Direitos Humanos de forma ininterrupta em seus dezessete anos de existência? Onde situar a imensa gama de informações nominativas contidas em prontuários e informes não só recebidos, mas emitidos diretamente por esse Ministério para os dirigentes máximos dos órgãos de segurança, visando atender aos pedidos seus e de suas representações diplomáticas no exterior? ${ }^{4} \mathrm{E}$ as extensas documentações de denúncias produzidas pelas organizações de Direitos Humanos, detalhadas e analisadas pelo departamento de Assuntos Especiais do MINREL e anexadas às suas correspondências, e que são transmutadas em fonte de informação para mapear as atividades da campanha subversiva promovida pelo "marxismo internacional", utilizando-as, desse modo, para inverter seu conteúdo, com o objetivo de invalidar suas denúncias e ações? Nesse caso, os arquivos dos Ministérios de Relações Exteriores, aqui tomados como exemplo, não se constituem somente de papéis estritamente

3"A Doutrina de Segurança Nacional (DSN) se baseava nos golpes contrainsurgentes, dando legitimidade às Forças Armadas de atuarem no cenário político dos países, na questão do ordenamento nacional. Na DSN, as pessoas exercem de fato sua cidadania pertencendo a uma comunidade nacional, e não a uma classe, gerando, assim, uma despolitização social. Coube às Forças Armadas restaurar a unidade nacional, que estava sendo ameaçada pela "subversão" e pelo "perigo comunista". Assim, a DSN formulou um "estado de guerra permanente" contra o "inimigo interno", que se estendi desde opositores abertos ao regime, como as organizações armadas, até qualquer pessoa que questionasse o sistema, todos identificados com o comunismo, conceito que se tornou extremamente flexível na utilização pela DSN”. Ver: Fernandes (2009, p.18-19).

\section{burocráticos.}

Possíveis respostas a estas indagações nos fornece Emmanuel Kahan, quando reflete que, sob a denominação de "arquivos da repressão”, podem ser encontrados diferentes repertórios de documentação com características variadas, levando ao debate sobre as particularidades dos fundos documentais vinculados aos períodos repressivos de cada instituição depositária. Nesse sentido, no reconhecimento de um arquivo como pertencendo "à repressão", situam-se as disputas acerca da importância de sua documentação para a elaboração de uma "memória coletiva", ou seja, a utilidade político/pública conferida à sua existência para dirimir disputas públicas e privadas que partem de indagações feitas no presente. No entanto, essa mesma documentação permite além do conhecimento do papel e das funções exercidas pelos organismos de inteligência política - compreender a dinâmica desigual do conflito entre as organizações da sociedade civil e o aparato repressivo do Estado (N. KAHAN, 2007).

Graciela Karababikian esclarece que não há acordo estabelecido para as denominações. Assim, tem-se que, costumeiramente, chama-se "arquivos da repressão" àqueles produzidos pelos órgãos repressivos legais ou ilegais das forças de segurança; "arquivos de direitos humanos" aos produzidos por pessoas ou organizações sociais que foram objeto da repressão, direta ou indireta, diríamos; "arquivos da memória" ou "arquivos da ditadura", esta última usada, na região do Cone Sul, para identificar o conjunto de todos eles: "denominaciones todas ellas con la que se quiere aludir más o menos a aquellos documentos que contienen información sobre los procesos represivos atravesados los países de Argentina y de la región”. A autora ressalta que, independente da denominação que possuam, estes arquivos possuem interesse jurídico, histórico e político, e que obtiveram notoriedade nos últimos tempos, na Argentina, não tanto pela tomada de consciência pública acerca da sua importância, mas devido ao fato de o Estado ter assumido o protagonismo na elaboração de políticas de memória, assim como de sua vontade política de reverter anos de indiferença quanto às violações dos Direitos Humanos ocorridas no país (KARABABIKIAN, p. 4; 6).

Por sua vez, Alberch I Fugueras centra sua atenção nos arquivos para os Direitos Humanos, e, salientando que é impossível estabelecer uma tipologia com valor universal, sugere uma aproximação que torne possível conhecer quais os arquivos que têm utilidade para as questões desses Direitos. Analisando as tipologias de arquivo realizadas por Jelin e Catela - fundos de instituições 
repressivas, de organismos de investigação sobre o passado, e das próprias associações de defesa dos Direitos Humanos -, Fugueras propõe uma aproximação mais exaustiva em um marco geral, onde estabelece a existência de três grandes grupos de arquivos de interesse, que são: os arquivos de organismos de Estado; os Privados; os constituídos a partir dos testemunhos recolhidos pelas Comissões para a Verdade e Reconciliação. No primeiro tipo ele situa os arquivos institucionais, que são formados, dentre outros órgãos, pelos arquivos nacionais ou gerais da Nação; os arquivos dependentes da presidência do governo, onde se estabelecem, em grande medida, os serviços de inteligência; os arquivos dependentes do Ministério do Interior, que geralmente englobam as direções de Polícia e as Forças de Segurança do Estado; os arquivos dependentes do Ministério de Relações Exteriores; os arquivos de organismos específicos de controle e repressão (serviços de informação, organizações paramilitares, tribunais de exceção, campos de concentração, prisões especiais, etc.) (ALBERCH I FUGUERAS, 2008, p. 81-83). Como se depreende, os "arquivos da repressão" se convertem, nesta definição, primeiramente em Arquivos para os Direitos Humanos, do qual fazem parte os arquivos de organismos/instituições do Estado, que englobam os "arquivos da repressão", aqui tidos como "organismos específicos de controle e repressão", não isolando e compartimentando, portanto, nesta conceituação, este tipo de arquivo - da repressão - e sua documentação.

Para Antonio González Quintana, responsável pelo resumo do Informe produzido pelo Grupo de Peritos constituído pelo Conselho Internacional de Arquivos (ICA) e a UNESCO, "la variedad de instituciones represivas es muy amplia ya que delimitar el alcance del término 'represión' no es sencillo", fazendo com seja preciso estender esse conceito aos âmbitos das ideias políticas, religiosas, condutas sexuais, etc. (GONZÁLEZ QUINTANA, 2005, p. 17). ${ }^{5}$ Partindo dessa constatação, González Quintana esclarece que o Grupo de Trabalho ICA-UNESCO estabeleceu as seguintes categorias de instituições repressivas:

Servicios de inteligencia, cuerpos paramilitares, tribunales especiales, campos de concentración, prisiones especiales, centros psiquiátricos para la "reeducación" y otros. Eso en cuanto a las instituciones especialmente creadas por los regímenes represivos y que están única y exclusivamente ligadas a la pervivencia de los mismos. Sin embargo encontramos también documentación represiva en instituciones tradicionales de la Administración que han continuado existiendo a la finalización de los regímenes totalitarios. Entre ellas el grupo ha establecido las siguientes categorías: Fuerzas Armadas, Policía y Cuerpos de Seguridad, Tribunales Ordinarios y Órganos de la Administración Civil (GONZÁLEZ QUINTANA, 2005, p.17, grifos nossos).

${ }^{5} \mathrm{O}$ livro constitui-se do Informe aprovado pelo Grupo de Expertos estabelecido pela UNESCO e o Consejo Internacional de Archivos, e que foi resumido por este autor. O Grupo de Trabalho, neste momento, reuniu dados sobre os arquivos de instituições
É de fundamental importância a distinção feita pelo Grupo de Trabalho, que, ao valer-se da terminologia de instituições repressivas que findam ou permanecem - nelas incluindo-se os serviços de inteligência criados pelas ditaduras e voltados à repressão, e a Polícia e corpos de Segurança, que permanecem após o final da ditadura - possibilita alargar o escopo do entendimento do que são os fundos ou séries documentais de caráter repressivo existentes nesses órgãos ou entidades. Apesar dos serviços de Inteligência possuírem documentação mais característica, tendo em seus arquivos informações que pressupõem sua localização imediata - caso das fichas, índices, prontuários, relatórios -, o entrelaçamento e entrecruzamento desses órgãos, ao gerarem intercâmbios de informação, possibilitam, muitas vezes, o entendimento do funcionamento global da "racionalidade do terror”, usando a expressão de Álvaro Abos. É bastante recorrente, no caso da documentação do Ministério das Relações Exteriores chileno, os pedidos de informação sobre pessoas desaparecidas feitos pelas Embaixadas locais onde se refugiaram ou se exilaram seus parentes ou amigos, ou mesmo de organizações da sociedade civil e organismos internacionais. Nestes casos, o caminho percorrido pelo MINREL é a solicitação de pedidos de antecedentes, via Ministérios do Interior ou Defesa, ou mesmo diretamente para os órgãos centrais de Inteligência, os quais, por seu turno, os entregam, invariavelmente, com as "explicações" de - "não consta"; "ignorado"; "desconhecido"; "posto em liberdade"; "morto em enfrentamento com a polícia” - perpetuando a insegurança e o desprestígio não só daquele do qual se pede a informação, mas, também, de quem a solicita: "La memoria del perseguido es denigrada, lo es su herencia y sus signos de identidad. [...] el cuerpo, la vida, el patrimonio, el hábitat, los restos y cenizas, el honor, la memoria, la vergüenza, todo ha de ser devastado" (ABOS, 1979, p. 10). A supressão, negação e encobrimento dos fatos inserem-se no círculo de retroalimentação da repressão direta, clandestina ou não. A perpetuação da mentira e da impunidade também demonstra toda a sua potencialidade nos arquivos dessa instituição.

Não menos importantes são as reflexões de Dario Olmo, integrante do Equipo Argentino de Antropologia Forense (EAAF), que demonstra a má interpretação feita acerca da disposição dos corpos das pessoas assassinadas por funcionários do Estado, devido ao fato de que o destino final a eles dado é vinculado ao circuito repressivo propriamente dito. Como os cadáveres eram, geralmente, jogados ao rio ou ao mar, ou abandonados em via pública, em simulações de enfrentamento com as forças de segurança, é somente nesta última alternativa que termina o circuito repressivo clandestino, iniciandose, então, a atuação do circuito denominado por Olmo de vegetativo ou burocrático. Contando com uma dinâmica completamente distinta, a fase burocrática do Estado segue os procedimentos legais para a identificação dos corpos encontrados em via pública. Como destaca o autor: "todos los pasos anteriores generaban gran cantidad

repressivas entre 1974 e 1994, da Alemanha, Brasil, Chile, Espanha, Hungria, Letônia, Lituânia, Paraguai, Polônia, Portugal, Rússia, África do Sul e Zimbabwe. O Informe foi aprovado pelo Grupo em reunião realizada em Salamanca, em dezembro de 1995. 
de material escrito, cuyo destino eran diferentes archivos administrativos" (OLMO, 2002, p.183-185). ${ }^{6}$ As fontes escritas utilizadas pela Equipe provinham de conjuntos documentais ordenados em dois critérios básicos: cronológico - documentos contemporâneos ou posteriores aos fatos; institucional - estatais ou não estatais. Desse modo é que os arquivos das forças repressivas, no caso tomado por Olmo o da Dirección de Inteligência de la Polícia de la Província de Buenos Aires (DIPBA), constituem-se em arquivos estatais contemporâneos aos fatos, assim como os tipos de arquivos institucionais mencionados por Fugueras, com a diferença de que os últimos não se extinguem com o fim do regime. De fato, como ressalta Pablo Policzer, essas instituições, reconhecidas internacionalmente como um "Estado", incluem o Executivo, o Legislativo e o Judiciário, delas fazendo parte suas burocracias subordinadas com atribuições diversas, desde implantar e fazer cumprir as leis, até coletar e distribuir informações. "Os regimes podem ir e vir, mas as instituições de governo - o Estado - tendem a permanecer. É claro que tais instituições são conformadas e afetadas pela natureza do regime, mas não se reduzem a ele" (POLICZER, 1998, p. 328-329).

Em relação ao arquivo da DIPBA, Olmo destaca duas características: sua subsidiariedade e sua hibridez. O primeiro se deve à atuação institucional deste órgão na repressão clandestina, que se subordinou à atuação das Forças Armadas, e por isso "al no hacerlo institucionalmente no produjeron informes que quedaron depositados em esa Policía" (OLMO, 2002, p.189-190). A característica híbrida provém da indefinição de sua localização em determinado setor, sendo metade burocrático, metade clandestino, recebendo informações próprias de serviços de inteligência, como informes secretos da "luta contra a subversão", sempre acompanhados dos selos "No difundir" ou "Estrictamente Confidencial o Secreto". O caráter híbrido é dado, então, porque este arquivo torna-se "un lugar donde conviven - y eventualmente interactúan - datos provenientes del costado clandestino con otros originados en el aparato burocrático" (OLMO, 202, p.192). Documentos com essas características abundam no arquivo do MINREL, nas informações prestadas pelos órgãos de Inteligência em resposta aos pedidos de Antecedentes formulados pelo próprio Ministério ou suas representações diplomáticas no Exterior, neste caso sempre com a intermediação da Chancelaria.

Como salienta González Quintana, os arquivos das instituições repressivas colocam problemas sociais que superam os limites da arquivística, ao possuírem uma enorme transcendência social e política (GONZÁLEZ QUINTANA, 2005). Nesse sentido, este autor nomeia os documentos "a serviço da repressão", que podem provir, a nosso ver, tanto de instituições diretamente vinculadas às forças de segurança e inteligência, quanto àquelas que, de modo indireto, porém não menos eficiente, além de terem em seus acervos cópias ou originais de diversos tipos de documentação expedida por esses organismos, têm, nas informações nominais ou de coletivos, condição fundamental para seu eficaz funcionamento de monitoramento no exterior, isto pressupondo informação constantemente reatualizada pelos serviços de Inteligência centrais. A condição da eficácia da informação é a sua retroalimentação. Esses "documentos a serviço da repressão", como salienta Quintana, além de aportarem o estudo de nosso passado recente, são essenciais para o exercício de Direitos, tanto coletivos quanto individuais, por isso extrapolando os limites arquivísticos (GONZÁLEZ QUINTANA, 2005). Acerca dos Direitos Coletivos, o Grupo de trabalho UNESCO-ICA elencou-os em um rol cada vez mais vigente:

1. O direito dos povos e nações de escolher sua própria transição política, condicionado à existência das fontes documentais institucionais sobre a repressão, para que exista plena liberdade de opções;

2. O direito à integridade da memória escrita dos povos é um direito irrenunciável, mesmo que se tenha pactuado pelo perdão ou pelo "esquecimento voluntário", pois o direito de escolher a via de transição política exclui o da destruição dos documentos;

3. O direito à Verdade, com informação global sobre a atuação do regime anterior;

4. Direito de conhecer os responsáveis por crimes contra os Direitos Humanos, saber o nome dos criminosos, dos agentes da repressão, mesmo com a existência de medidas de graça como a anistia ou o indulto, porque em uma democracia os povos devem conhecer os nomes dos responsáveis pelas atrocidades cometidas, evitando possíveis promoções políticas amparadas no anonimato dos crimes contra os Direitos Humanos.

Quanto aos Direitos Individuais, o Grupo elenca seis deles, que, acrescidos aos anteriores, fazem recair sobre as instituições arquivísticas uma "desconhecida realidade", que requerem do profissional arquivista uma reflexão profunda a respeito da gestão de tais fundos:

1. Direito de conhecer o paradeiro de familiares desaparecidos no período;

2. Direito ao conhecimento dos dados existentes sobre qualquer pessoa nos arquivos repressivos (habeas data);

3. Direito à pesquisa histórica e científica;

4. Direito à Anistia para os presos e os que foram vítimas de represálias políticas;

5. Direito à compensação e reparação de danos sofridos pelas vítimas da repressão;

6. Direito à restituição de bens confiscados.

Porém, é o próprio redator destas palavras que nos indica quão 
longe estamos das suas efetivas e necessárias realidades. González Quintana, ciente da necessidade de medidas que garantam a preservação dos fundos documentais que contribuam para a concretização desses Direitos, diz não ser frequente que os arquivistas encontrem interlocução com outros coletivos sociais, aos quais não conseguem transmitir a importância de conservar e tratar esses acervos que possibilitam o exercício dos Direitos dispostos em Lei. Salientando que a mídia, a imprensa ou mesmo o cinema usaram esses arquivos como fonte de denúncia ou para exigir responsabilidades políticas, nada se diz sobre a importância da conservação e tratamento dos documentos que possibilitaram a construção desses relatos: "Deberíamos concluir, pues, que la importancia que los archiveros damos a los archivos como instituciones no se corresponde a la que le dan sus usuários" (GONZÁLEZ QUINTANA, p. 5-6), e poderíamos acrescentar, os sucessivos governos que ignoram as condições por vezes precaríssimas dos arquivos estatais de suas esferas de competência.

\section{DOCUMENTOS DAS INSTITUIÇÕES REPRESSIVAS}

A maior característica de distinção que portam os documentos das instituições da repressão é o denominado "efeito bumerangue" atípico e único, nas palavras de González Quintana -, quando os próprios documentos gerados para a repressão passam a constituir provas das práticas de Terror de Estado, fundamentando o exercício dos Direitos individuais e coletivos acima elencados. Como destaca Ana Maria Camargo, os documentos de arquivo possuem o traço distintivo de serem produzidos de forma rotineira, primando por imperativos de ordem prática, não tendo nenhuma pretensão de informar à posteridade (CAMARGO, 2002, p. 4). Ou seja, o uso secundário para o qual possam ser utilizados não está inscrito, necessariamente, em seu uso instrumental original, o que não significa que não existisse controle e cuidado quanto à sua produção por parte dos órgãos institucionais a que se referem e destinam.

Essa distinção, no que tange aos arquivos repressivos, nos conduz a outras duas, que dizem respeito à autenticidade dos testemunhos dos detidos e à veracidade das informações compiladas, uma vez que, especialmente nos arquivos dos órgãos de informação e inteligência, há o acúmulo de informações nominativas que se constituem de apreciações ou juízos de valor sobre pessoas concretas, explicitamente designadas. No entanto, essas informações pessoais são, em grande parte das vezes, improcedentes, inexatas e enganadoras, pois a metodologia empregada para obtê-las inclui, dentre outras, tortura, pressão psicológica e encarceramento, muitas vezes clandestino (ALBERCH I FUGUERAS, 2008, p. 62; CAMARGO, 2002, p. 3). No entanto, essas documentações, por seu caráter probatório, constituem-se, elas próprias, em testemunhos do funcionamento da máquina repressiva, provando as práticas de terror de Estado, mesmo que os documentos as silenciem ou que os Estados as ocultem: "En este sentido serán documentos válidos para el ejercicio de derechos como al amnistía o la reparación y compensación de las víctimas de la represión" (GONZÁLEZ QUINTANA, 2005, p. 19).

No que tange ao caráter probatório dos arquivos das instituições repressivas, Camargo assevera que isso é uma "vocação", pois os documentos são partes de um conjunto que lhes proporciona relação orgânica entre si, daí advindo que os "documentos carregam consigo, obrigatoriamente, a cunha da instituição que os produziu" (CAMARGO, 2002, p. 8). Este organismo é o que confere autenticidade à documentação, porque, para serem interpretados, temos que saber as razões de por que foram produzidos ou as condições que os originou, ou seja, buscar informações sobre a natureza contextual do arquivo que se encontram fora do conteúdo específico da documentação; já no que toca à veracidade, esta somente pode ser alcançada com a verificação do material empírico, em um processo de contraste de fontes e outros acervos documentais. Desse modo é que os documentos das instituições repressivas são legítimos, autênticos e têm valor de prova - "São os conjuntos - a série documental, o arquivo e a instituição que lhe deu origem - que prestam relevância à informação" (CAMARGO, 2002, p. 8-9).

Temos que ter em conta, também, que os dados inscritos nessa documentação dizem respeito a pessoas vivas, sejam elas vítimas ou vitimários, seus parentes ou amigos. Isto lhes acresce outros valores, além do judicial e histórico, que são os de memória e de identidade, ratificando a verdade e a realidade dos testemunhos das vítimas. Tanto podem desmentir as alegações feitas pelos implicados na repressão, que tudo negam ou distorciam, ou legitimar as "memórias lastimadas" (SILVA CATELA, 2002, p. 210; 212) dos que sofreram perseguições, prisões em centros clandestinos, torturas, mortes e desaparecimentos forçados. O efeito bumerangue dos documentos dos arquivos das instituições repressivas possibilita, em grande medida, reconstruir e confirmar parte das histórias de suas vítimas.

Nesse sentido, o Grupo de Trabalho ICA-UNESCO fornece uma "tipologia dos delitos" que devem ser identificados nos documentos a serem selecionados e separados, no caso de fundos abertos que continuam existindo após o término dos regimes ditatoriais. $\mathrm{O}$ profissional arquivista, neste caso, deve sempre ter como objetivo o estabelecimento de um prazo pré-determinado para fazer a restituição da integridade do fundo, porque, do contrário, poderia incorrer no erro de invisibilizar o papel que essas instituições tiveram na sistematização e operacionalização racional/burocrática da repressão Estatal. Esse rol, que não se pretende exaustivo, elenca os delitos que devem ser considerados inexistentes, e que, acrescentamos, foram aos seus tempos criados, manipulados e inscritos à figura da "subversão" que se queria debelar, servindo como justificativa legal para prisões, sequestros, submissões a Tribunais de Guerra, etc. Dentre estes, menciona-se: ameaças à autoridade e a particulares; coligação ilegal; contra a legislação especial e a segurança interior do Estado; desacato; desobediência; 
greves; infração do código de Justiça Militar; injúrias e insultos a autoridades; manifestação ilegal; objeção de consciência; passagem clandestina de fronteiras; imprensa e propaganda ilegal; rebelião; resistência; reunião ilegal; sedição (GONZALEZ QUINTANA, 2005).

Em razão dos documentos dos arquivos das instituições repressivas não conterem "toda a verdade" de suas afirmações, implica, também, encarar as suas "mentiras" sob outra perspectiva que os distinguem, que é o fato, apontado por Jelin, de estarem inseridos em regimes onde a arbitrariedade e a clandestinidade foram a norma (a regra) da ação do Estado, disto resultando que muitas das ações praticadas não deixaram registro escrito ou documental (JELIN, 2002, p. 3). Essa é uma característica forte a reter, ambientando a produção dos conjuntos documentais dos órgãos de repressão "direta ou indireta" em um processo racional de repressão ao "inimigo" que se torna a própria razão de Estado. Abos adverte sobre essa tensão existente entre a necessidade das operações punitivas do Estado serem secretas, a fim de serem "eficientes", e a sua "exemplaridade", pois, ao admiti-las, ele estaria também declarando a sua própria ilegitimidade (ABOS, 1979, p. 13-14). Hannah Arendt, escrevendo sobre o julgamento do nazista Adolf Eichmann e a banalização do mal, nos fornece elementos para analisar o porquê da mentira nessa documentação:

A acusação tinha por base a premissa de que o acusado, como toda "pessoa normal", devia ter consciência da natureza dos seus atos, e Eichmann era efetivamente normal na medida em que "não era uma exceção dentro do regime nazista”. No entanto, nas condições do Terceiro Reich, só se podia esperar que apenas as "exceções" agissem "normalmente". (ARENDT, 1999 p. 38)

Nesse sentido é que a mentira nos documentos da repressão é "normal" - por não ser "exceção" -, pois nas circunstâncias em que se dá não se espera encontrar nessas correspondências proposições diretas que deem conta da verdadeira face da violência praticada enquanto política racional de terror de Estado. Bem pelo contrário, além de sempre negar e tergiversar sobre a realidade dos fatos, há todo um arcabouço de normas de redação e linguagem padronizada, "regras de linguagem" que, como salienta esta autora, é "um codinome; significava o que em linguagem comum seria chamado de mentira” (ARENDT, 1999, p. 101).

Há, portanto, que proceder ao devido exame crítico da documentação, a fim de verificar seu caráter probatório, isto importando em sua conservação, pois a ausência de provas documentais, muitas vezes devida à sua destruição intencional por parte do Estado, está diretamente relacionada ao fortalecimento da já existente impunidade (ALBERCH I FUGUERAS, 2008, p. 6162). Se as fontes não existem ou, quando sim, estão repletas de inexatidões, os mencionados processos de coleta de informações sobre a natureza contextual do arquivo, bem como o de contraste de fontes e outros acervos documentais, são operações intimamente relacionadas com o fazer histórico. Isto é salientado por Cristina Garcia Gutierrez, ao ressaltar que os arquivos das instituições da repressão são fontes de grande importância para a análise do período ditatorial, mas que não podem ser as únicas. Esta autora elenca dois motivos principais para sua assertiva: o primeiro se dá pelo fato, já aqui apresentado, de que muitos desses arquivos permanecem ocultos; o segundo se relaciona aos arquivos que foram encontrados e estão disponíveis, pois as pesquisas neles realizadas ratificam as conclusões extraídas da análise de outras fontes, reforçando, assim, a perspectiva de que os "arquivos da repressão" não contêm "toda a verdade". Esse caráter mentiroso e às vezes inventado das informações contidas nos documentos é o fator apontado para a necessidade de que sejam analisados por pesquisadores que conheçam o período e os códigos de linguagem gerados pela ditadura. Para Garcia Gutierrez "las fuentes de los organismos represores no son fuentes de primera clase en comparación con otras que relatan la represión del periodo" (GARCIA GUTIERREZ, 2010, p. 1722), ou seja, não se bastam em si mesmas, havendo a necessidade de serem contrastadas para obtermos dados que se aproximem o máximo possível da realidade do momento; sempre com o entendimento, conforme nossa perspectiva, de que o passado que a história tem como objeto é uma realidade exterior ao discurso. Esses postulados acerca da necessidade do conhecimento do período a que se refere a documentação, podem ser inferidos nas palavras de Catela, quando destaca que os silêncios e vazios, o não documentado, também são "dados", e que essas ausências precisam ser percebidas e interpretadas (DA SILVA CATELA, 2002, p. 208).

A importância do cruzamento de fontes também é salientada por Anne Pérotin-Dumon, para quem a diversidade de provas é elemento importante para demonstrar que algo aconteceu, e qual o seu grau de concordância: "una fuerte coincidencia entre fuentes de orígenes muy diversos permite, en efecto, concluir con un significativo 'grado de certidumbre en el establecimiento de los hechos"' (PÉROTIN-DUMON, 2005, p. 42-43). Esta autora, tal como Garcia Gutierrez, vale-se do exemplo dos arquivos das Comissões da Verdade - em seu caso o cotejamento de dados efetuado pela Comisión Nacional sobre Prisión Política y Tortura, responsável pela feitura do Informe Valech, entregue no ano de 2004, no Chile - para demonstrar o caráter imprescindível desse processo, pois os testemunhos prestados pelas vítimas foram complementados, retificados ou ratificados com arquivos dos diferentes serviços e organismos do Estado (conservados no Arquivo Nacional do Chile), nos acervos das múltiplas organizações de Direitos Humanos nacionais, bem como arquivos internacionais, dentre eles os das Embaixadas que outorgaram asilo a cidadãos chilenos ${ }^{7}$ 
Miranda, seguindo as reflexões de Tom Nesmith, para quem "o trabalho de arquivo é impulsionado por um imperativo histórico primordial", salienta que o estudo da História é condição para os trabalhos de Arquivo, não somente para levantar a história administrativa de órgãos, entidades e instituições (como também de pessoas físicas, no caso dos acervos privados), mas, também, para a compreensão do contexto de produção e para a avaliação documental (MIRANDA, 2011, p. 10-11), que é uma prerrogativa de seleção sobre aquilo que passa a ser o material passível de arquivamento.

Como ressalta Roberto Pittaluga, a atividade do arquivo não consiste em reunir materiais documentais do passado, mas, sim, produzir aquilo que a partir desse momento passa a ser o arquivável, ou seja, selecionar o que deve ou não ser preservado: "Una política de archivo es, en todo momento, una política sobre lo que se recuerda y lo que se olvida, una política de memoria, una dimensión de la escritura de la historia" (PITTALUGA, p. 2-4). A prática do arquivo outorga um lugar - físico e social - ao objeto que se converterá em documento para a operação historiográfica; um lugar que permite e que próbe, ressalta atributos e invisibiliza outros, estabelece conexões. Para tanto, esta prática se vale de regras e critérios que estabelecem o que se considera fontes para a história; critérios e regras estes que não são imunes às divisões e conflitos sociais e políticos, podendo levar, por um lado, às tentativas de negação dos acontecimentos (como ocorre com os desaparecidos políticos), e, por outro, ao condicionamento das relações que se possa estabelecer com o passado, com o ocultamento (ou destruição) dos arquivos dos órgãos de repressão. É desse modo que Pittaluga salienta que devemos pensar não somente na questão do arquivo da repressão, mas da repressão do arquivo, do arquivo reprimido como poder do Estado sobre o historiador, expressão esta de Sonia Combe utilizada pelo autor, remetendo a uma noção do arquivo como propiciador de diferentes perguntas e formas de escrita da história, algumas possíveis, outras não (PITTALUGA, p. $4-6)$.

Por outro lado, a História pode negligenciar/ressignificar histórias e memórias. Enzo Traverso chama a atenção para a influência da História sobre a memória em si, salientando que não existe memória literal, original e não contaminada, pois ela é uma visão do passado sempre filtrada pelo presente. A memória, embora seja reelaborada constantemente por outras inscritas no seio do espaço público, também é influenciada pelos paradigmas científicos de representação do passado (TRAVERSO, 2005, p. 20; 29); isto é, o que está imbuído de "autoridade" por seus pares, que lhe reconhecem a legitimidade, necessidade ou validez enquanto construção de saber.

A memória, por sua vez, por partir de interrogações feitas no presente, propicia que este determine suas modalidades - seleção dos eventos que precisam ser lembrados e, consequentemente, dos testemunhos a serem escutados; sua interpretação e "lições" a tomar -, tomando, muitas vezes, uma dimensão política - e os abusos que isso acarreta - que afetam a maneira de escrever a história (TRAVERSO, 2005, p. 16-17). Oliver Lalieu ressalta que na França o "dever de memória", formulado a partir da década de 1990 pelas vítimas do Holocausto, proporciona o caráter de "ensinamento" e visibilidade às novas gerações, com os testemunhos adquirindo, assim, uma função social, dado que as pessoas que sofreram os horrores do nazismo têm um maior respaldo para vir a público a fim de afrontar tanto o negacionismo quanto o revisionismo históricos, movimentos que negam a própria existência desses que testemunham (LALIEU, 2001, p. 93). Reflexões estas feitas por Traverso, mas em sentido inverso; por um lado, quando a memória não pode ser elaborada e inscrita no espaço público, ela se alça, mais do que contra o esquecimento, contra aqueles que ocultam e negam o crime no presente. Por outra parte, a escrita da história fica entravada, pois a ocultação passa pelo fechamento de arquivos e a multiplicação de obstáculos à pesquisa (TRAVERSO, 2005, p. 47).

Os arquivos influenciam diretamente a escrita da história e a preservação de memórias; a escrita da história influencia as memórias; as memórias influenciam a escrita da história; em uma dialética na qual cada elemento se inscreve, necessariamente, no conjunto de relações de força que a sustenta e legitima.

Há memórias oficiais, vinculadas aos Estados; memórias subterrâneas, escondidas ou interditadas, pois "a visibilidade e o reconhecimento de uma memória dependem também da força desses que a carregam. Dito de outro modo há memórias 'fortes' e memórias 'fracas"' (TRAVERSO, 2005, p. 54). No entanto, Traverso assinala que força e reconhecimento não são fixos e imutáveis, podendo evoluir, se consolidar ou enfraquecer, ou seja, o que hoje é passível de ser lembrado, amanhã pode não o ser; o que hoje se erige como memória do passado, amanhã pode estar na "clandestinidade". A permanente interação entre memória/história resulta “em uma relação privilegiada entre as memórias 'fortes' e a escrita da história. Quanto mais a memória é forte - em termos de reconhecimento público e institucional -, mais o passado é susceptível de ser explorado e colocado na história” (TRAVERSO, 2005, p. 63-64). Longe de possuir uma relação mecânica de causa e efeito entre estes dois vetores - força da memória e historicizar o seu passado -, esta relação se submete a mediações diversas, sendo também diferentes os contextos em que ocorrem.

As reflexões de Traverso acerca da existência dessas memórias "fortes" e "fracas" podem ser extensivas para pensar o quanto as conjunturas políticas determinam, também, a abertura dos arquivos e a validade de seus conjuntos documentais.

\section{CONSIDERAÇÕES FINAIS}

Arquivos da repressão; das instituições repressivas; de instituições de repressão; arquivos sobre a atividade repressiva do Estado; 
arquivos sobre a repressão; arquivos alternativos; arquivos das instituições do Estado; arquivos de Direitos Humanos; arquivos da memória, arquivos da ditadura: diferentes terminologias que remetem à necessária utilização da documentação a serviço das diversas modalidades de repressão exercidas pelo terror de Estado para a garantia e consagração de Direitos coletivos e individuais, que vão desde os direitos pela memória, verdade e Justiça, até os de pesquisa histórica e científica. Todos têm o direito de saber e escrever sobre "este passado que não passa", modo de dizer corrente para se referir à questão da impunidade, como negação violenta da realidade que é. Trata-se de Direitos Humanos, ao fim.

Verifica-se que as ações que se valem de torturas, mortes e sequestros seguidos de desaparecimentos se dão, na maior parte das vezes, em situações e locais ilegais e clandestinos, com os registros explícitos dessas modalidades repressivas inexistindo na documentação até o momento conhecida. Contudo, uma parcela significativa dessa documentação dos órgãos específicos de coerção e controle pode ser encontrada nos fundos documentais das instituições "legais" do Estado - como no Ministério de Relações Exteriores do Chile, por nós utilizado como exemplo, que reproduz e distribui múltiplas cópias desses documentos que lhes são enviados pelas Agências Centrais da polícia política chilena, constando de pedidos de informação de diferentes índoles antecedentes, memorandos, boletins, pareceres, informes, prontuários -, e, em sentido inverso, essas mesmas Agências lhe solicitam informações das mais variadas atividades, da resistência à ditadura feita no exterior, constando mesmo, por vezes, longas transcrições de reuniões partidárias feitas por agentes infiltrados nessas organizações. Pode-se inclusive remontar grande parte da estrutura repressiva valendo-se dessas imbricações e retroalimentação de informação. Para Gerardo Caetano, que confirma o caráter fortemente burocrático das instituições vinculadas, nesse caso, à ditadura no Uruguai, é de fundamental importância aprofundar as buscas dos documentos para a repressão nas instalações não só das Forças Armadas, mas nos Ministérios da Defesa e do Interior (CAETANO, 2011, p. 15), ou seja, em arquivos vinculados de forma direta ou indireta com a repressão. Com efeito, no caso chileno verifica-se que boa parte dos "arquivos da repressão" está contida no acervo documental de seu Ministerio de Relações Exteriores.

Para que determinado conhecimento científico seja validado, existe a necessidade da legitimação desse saber, e isso implica em seleção, confluindo no campo do conhecimento histórico (o que deve ou não ser erigido a objeto de estudo), identificação/preservação de fundos arquivísticos (quais devem se constituir como fontes de pesquisa, quais os critérios e práticas que os alçam a esta condição ). É assim que arquivo, história e memória se entrecruzam nesta seleção, por vezes mais ou menos arbitrária, de eventos e fontes.

!No más archivos secretos!; As questões relacionadas à abertura dos arquivos das instituições repressivas costumeiramente esbarram em seus limites, que são ir "até onde for possível" no que tange ao papel dos Estados de assumirem suas responsabilidades ante as vítimas - lhes fazendo a tão necessária Justiça -, e perante o conjunto da sociedade, pois, afinal, esta é uma história que pertence a todos.

\section{REFERÊNCIAS}

ABOS, Álvaro. La racionalidad del terror. El Viejo Topo, n. 39, p. 9 14, dic. 1979.

ALBERCH I FUGUERAS, Ramon. Archivos y Derechos Humanos. Gijón (Asturias): TREA, 2008.

ARENDT, Hannah. Eichmann em Jerusalém: um relato sobre a banalidade do mal. São Paulo: Companhia das Letras, 2013.

CAETANO, Gerardo. Los archivos represivos em los procesos de "justicia transicional": una cuestión de derechos. México FLACSO, Perfiles Latinoamericanos, n. 37, p. 9-32, ene-jun. 2011.

CAMARGO, Ana Maria de Almeida. Os arquivos da polícia política como fonte. Registro. Revista do Arquivo Público Municipal de Indaiatuba, v. 1, n. 1, jul. 2002.

DA SILVA CATELA, Ludmila. El mundo de los archivos. In: SILVA CATELA, Ludmila; JELIN, Elizabeth (comps.). Los archivos de la represión: documentos, memoria y verdad. Madrid: Siglo Veintiuno, 2002. p. 195-221.

DINGES, John. Un bombazo sobre la culpabilidad de Pinochet, recibido muy tarde. The Clinic, 25 oct. 2015. Disponível em: < http://www.theclinic.cl/2015/10/25/un-bombazo-sobre-laculpabilidad-de-pinochet-recibido-muy-tarde/>. Acesso em: 25 out. 2015.

FERNANDES, Ananda Simões. Quando o inimigo ultrapassa a fronteira: as conexões repressivas entre a ditadura civil-militar brasileira e o Uruguai (1964-1973). 2009. 274 f. Dissertação (Mestrado em História) -Programa de Pós-Graduação em História, Instituto de Filosofia e Ciências Humanas, Universidade Federal do Rio Grande do Sul, Porto Alegre, 2009.

FERNANDES, Ananda S.; SIMÕES, Sílvia. Apontamentos sobre a conexão repressiva entre as ditaduras brasileira e chilena. Albuquerque: Revista de História, Campo Grande, MS, v. 6, n. 11, p. 121-152, jan./jun. 2014

GARCIA GUTIERREZ, Cristina Luz. Fuentes para el estudio de la represión en Iberoamérica : entre archivos y centros documentales. Congreso Internacional 1810-2010 : 200 años de Iberoamérica XIV Encuentro de Latinoamericanistas Españoles. Santiago de 
Compostela, 2010. p. 1716-1733.

GONZÁLEZ QUINTANA, Antonio. Los archivos de la seguridad del Estado de los desaparecidos regímenes represivos. Salamanca: Ica-Unesco, 2005. Disponível em:< http://portal.unesco.org/ci/en/files/4979/10325906731LOS_ARC HIVOS_DE_LA_SEGURIDAD_DEL_ESTADO_DE_LOS_DES APARECIDOS_REG\%CDMENES_REPRESIVOS.doc $>$. Acesso em : 16 mai. 2014.

El impacto de los archivos sobre la sociedad. Memoria Abierta - Materiales de Lectura. Disponível em: <http://www.memoriaabierta.org.ar/materiales/pdf/antonio_gonz alez_quintana.pdf $>$. Acesso em : 22 fev. 2015.

JELIN, Elizabeth. Introdución. Gestión Política, Gestión Administrativa y Gestión Histórica: ocultamientos y descubrimientos de los archivos de la represión. In: SILVA CATELA, Ludmila; JELIN, Elizabeth (Comps.). Los archivos de la represión: documentos, memoria y verdad. Madrid: Siglo Veintiuno, 2002. p. 1-13.

KARABABIKIAN, Graciela. Archivos y derechos humanos en Argentina. Memoria Abierta - Materiales de Lectura. Disponível em:

http://www.memoriaabierta.org.ar/materiales/pdf/archivos_y_der echos_humanos.pdf>. Acesso em : 22 fev. 2015.

LALIEU, Oliver. "L'invention du devoir de memoire”. Vingtième Siècle, Revue d'histoire. Paris, Année 2001, v. 69, n. 1, p. 83-94.

MIRANDA, Marcia Eckert. Historiadores, Arquivistas e Arquivos. Anais do XXVI Simpósio Nacional da ANPUH Associação Nacional de História, 2011, São Paulo. Disponível em : $<$ http://www.snh2011.anpuh.org/conteudo/view?ID_CONTEUD $\mathrm{O}=775>$. Acesso em : 11 set. 2015.

N. KAHAN, Emmanuel. ¿Qué represión, qué memoria? El “archivo de la represión” de la DIPBA: problemas y perspectivas. Revista Question, Facultad de Periodismo y Ciencias de la Comunicación da Universidad Nacional de La Plata, n. 16, 2007.

OLMO, Dario. Reconstruir desde restos y fragmentos. El uso de archivos policiales en la Antropologia Forense en Argentina. In: SILVA CATELA, Ludmila; JELIN, Elizabeth (comps.). Los archivos de la represión: documentos, memoria y verdad. Madrid: Siglo Veintiuno, 2002. p. 179-194.

PADRÓS, Enrique Serra. Como el Uruguay no hay... Terror de Estado e Segurança Nacional. Uruguai (1968-1985): do Pachecato à ditadura civil-militar. 2005. $434 \mathrm{f}$. Tese (Doutorado História) - Programa de Pós-Graduação em História, Instituto de Filosofia e Ciências Humanas, Universidade Federal do Rio Grande do Sul, Porto Alegre, 2005.
PÉROTIN-DUMON, Anne. El pasado vivo de Chile en el año del Informe sobre la tortura. Apuntes de una historiadora. Nuevo Mundo Mundos Nuevos - Revues.Org. Debates 2005. Disponível em : <https://nuevomundo.revues.org/954?lang=pt>. Acesso em : 16 abr. 2009

PITTALUGA, Roberto. Democratización del archivo y escritura de la historia. Memoria Abierta - Materiales de Lectura. Disponível em : $<$ http://www.memoriaabierta.org.ar/materiales/pdf/roberto_pittal uga.pdf>. Acesso em : 22 fev. 2015

POLICZER, Pablo. A Polícia e a Política de Informações no Chile durante o governo Pinochet. Estudos Históricos, Rio de Janeiro, v. 12 , n. 22 , p. $325-356,1998$

TRAVERSO, Enzo. Le passé, modes d'emploi: histoire, mémoire, politique. Paris: La Fabrique, 2005. 